\title{
Estudios geométricos y constructivos de una bóveda tabicada de yeso en la Comunidad de Madrid: determinación de su autoría por Juan Guas
}

\author{
Rocío Maira Vidal
}

Resumen: Este trabajo presenta los resultados del estudio geométrico y constructivo de la bóveda de crucería del presbiterio de la iglesia parroquial de Nuestra Señora de las Nieves, en Manzanares El Real, al norte de la Comunidad de Madrid. Las obras de restauración que la Dirección General de Patrimonio Histórico de la Comunidad de Madrid junto con el Arzobispado de Madrid están llevando a cabo sobre el edificio, han permitido realizar diversas investigaciones entre las que se encuentra este trabajo. En primer lugar se llevó a cabo una toma de datos precisa con herramientas topográficas. Sobre estas mediciones se abordó el análisis de la traza de la bóveda, su montea y su proceso constructivo. Este estudio, apoyado en los demás trabajos de investigación, ha permitido determinar su autoría.

Palabras clave: Bóveda; Yeso; Tabicada; Juan Guas; Moldes; Montea; Construcción; Gótico; Baivel.

Estudos geométricos e construtivos de uma abóboda tabicada de gesso, na Comunidade de Madrid: a identificação do autor Juan Guas

Resumo: Este artigo apresenta os resultados do estudo geométrico e construtivo da abóbada de cruzaria da capela-mor da igreja paroquial de Nossa Senhora das Neves, em Manzanares El Real, a norte da Comunidade de Madrid. Os trabalhos de restauro no edifício, levados a cabo pela Direcção-Geral do Património da Comunidade de Madrid, juntamente com a Arquidiocese de Madrid, permitiram desenvolver diversas investigações, onde se inclui este trabalho. Em primeiro lugar, procedeu-se ao registo de dados precisos, com ferramentas topográficas. A partir dessas medições, analisou-se a traça da abóboda, sua montagem e seu processo construtivo. Este estudo, apoiado nos demais trabalhos de investigação, permitiu determinar a sua autoria.

Palavras-chave: Abóboda; Gesso; Tabicada; Juan Guas; Traça; Construção; Gótico; Esquadro e compasso.

Geometric and construction studies of a tabique plaster dome, in the Community of Madrid: the author's identification Juan Guas

\begin{abstract}
This paper presents the results of the geometric and constructive study of the rib vault in the apse of Nuestra Señora de las Nieves Church located in the town of Manzanares El Real (Madrid, Spain). The Dirección General de Patrimonio Histórico de la Comunidad de Madrid (the department of heritage of the regional government of Madrid) and the Archbishopric are carrying out restoration works on the building that have allowed us to develop several researches, like this study. First of all there have been taken accurate measures with a total station. This measurement has allowed us to study the geometric rules and its constructive process. This research, supported on the other studies realised, made possible to identify the project authorship.
\end{abstract}

Key words: Vault; Plaster; Tile vault; Juan Guas; Geometric trace; Construction; Gothic; Mason 'square.

\section{Obras de restauración en la iglesia parroquial de Manzanares}

La iglesia de Manzanares fue construida entre finales del siglo XV y mediados del siglo XVI. En ese momento la poderosa familia de los Duques del Infantado estaba construyendo el castillo, próximo a la iglesia, bajo la dirección del arquitecto Juan Guas.

Su planta de tipo basilical tiene tres naves. En su fachada sur se desarrolla un atrio con pórtico renacentista. Tiene una torre de planta cuadrada adosada a los pies, en su lado noroeste. Toda la 
fábrica del templo es de mampostería de granito, a excepción de la actual capilla y del último cuerpo de la torre, ejecutados con sillería del mismo material. En el presbiterio encontramos una bóveda tabicada de yeso, objeto de esta investigación. La capilla aneja está también cubierta por una bóveda de crucería, en este caso de rosca de ladrillo y nervios de piedra.

La última intervención, realizada en la iglesia durante los años setenta, había sustituido la cubierta de la nave central. Además de las carencias funcionales que ofrecían las soluciones aplicadas, éstas distorsionaban notablemente el espacio interior y no se integraban en el edificio.

En el año 2008 se planteó la restauración del templo, acometiendo posteriormente las obras necesarias para su conservación en el marco del Convenio suscrito entre el Arzobispado de Madrid y la Dirección General de Patrimonio Histórico de la Comunidad de Madrid.

Para ello se acometieron previamente las investigaciones pertinentes. Se realizó una lectura de paramentos además de un estudio histórico-artístico'. Ambos llegaron a las mismas conclusiones: la iglesia parroquial de Manzanares el Real, guarda relación con la construcción del Castillo Nuevo de Manzanares (1475-1480) y las obras del palacio del Infantado de Guadalajara (1480 -1483)2. En ese momento don Iñigo López de Mendoza y Luna era el Conde del Real de Manzanares. El estudio histórico concluye que las tres obras debieron estar a cargo del equipo de constructores alarifes dirigidos por Juan Guas y sitúa la construcción de la bóveda que nos ocupa posterior al año 1479.

Por otro lado se tomaron muestras de los morteros existentes en distintas partes de la bóveda del presbiterio para conocer su morfología y composición ${ }^{3}$. Estos morteros fueron analizados mediante espectroscopia infrarroja por transformada de Fourier (FTIR por transmisión y FTIR-ATR) ${ }^{4}$. En los resultados se confirmó que todos los morteros de la bóveda (nervios, plementería, trasdós, etc.) estaban hechos enteramente de yeso. La presencia de cal solo se encontró en el mortero de los muros de la cabecera.

Se contactó también con el Ayuntamiento y con las organizaciones culturales del municipio para que aportasen la documentación e información que estimasen oportuna ayudando así en el desarrollo de la actuación.

Una vez recopilados todos los datos, el arquitecto Antonio Ábalos desarrolló el proyecto arquitectónico [Figura 1], que junto con las directrices y prescripciones indicadas por los técnicos de la Dirección General de Patrimonio Histórico, llevarán a la ejecución de las obras actualmente en curso. Se pretende poner en valor el elemento patrimonial y para ello se recupera la altura perdida de los volúmenes originales, planteando soluciones constructivas modernas que se manifiesten de manera natural, integradas en el contexto general ofrecido por el edificio histórico objeto de intervención.

La bóveda del presbiterio ha sido estudiada especialmente, como veremos a continuación, ya que no se ha conservado documentación alguna sobre ella, y por su factura se pensó en un principio que era de construcción reciente.

Las distintas investigaciones realizadas en el edificio, tratadas en equipo entre todos los intervinientes, han permitido detectar los valores que guardaba en su interior. 

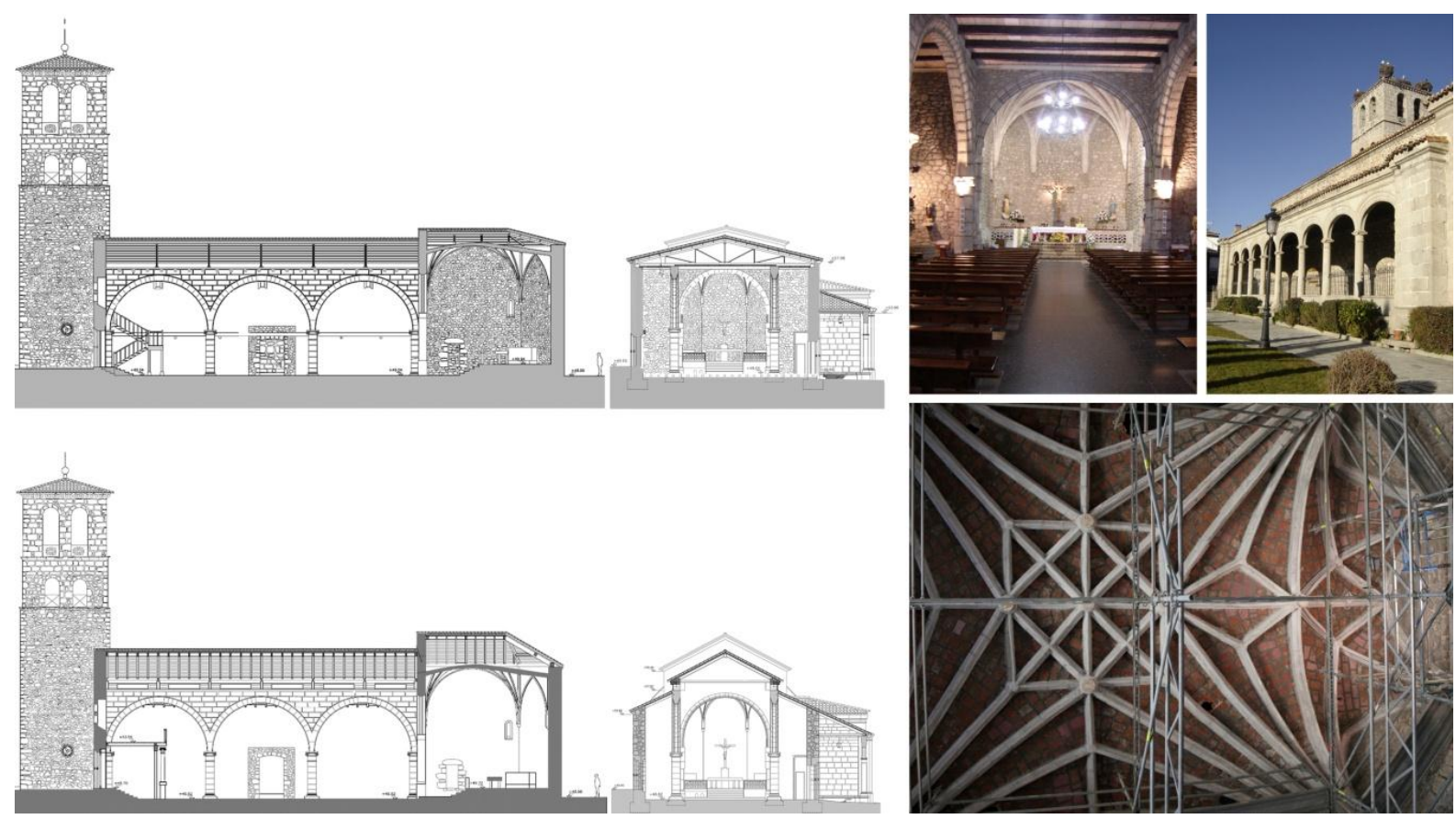

Figura 1. Arriba planos y fotos del estado inicial, abajo planos del proyecto de restauración: cortesía de Antonio Ábalos. Abajo a la derecha imagen de la bóveda objeto de la investigación.

\section{Propósito, objetivos y relevancia de la investigación}

La dirección facultativa de la obra encargó el levantamiento topográfico de la bóveda para poder documentar detalladamente una de las piezas más importantes del edificio.

Siendo tabicada de yeso en una localización con canteras próximas y con el resto de la iglesia construida en piedra, se presentaba como un elemento extraño en su contexto. Una vez llevadas a cabo las investigaciones de caracterización de materiales, se determinó que el ladrillo de su plementería databa del siglo XV-XVI. Esta datación de la bóveda se llevó a cabo por el método de termoluminiscencia, aplicado en materiales cerámicos, con el fin de establecer su momento de cocción. Se tomaron dos muestras del ladrillo de su plementería ${ }^{5}$ que fueron analizadas en el Laboratorio de datación y radioquímica de la Universidad Autónoma de Madrid ${ }^{6}$.

Una vez datada la bóveda se planteó realizar su estudio pormenorizado. Los arquitectos del gótico tardío diseñaban y construían sus bóvedas basándose en un profundo estudio geométrico, por lo que se abordó esta investigación con el fin de aportar información sobre su autoría, (se ha dispuesto un glosario al final del artículo para facilitar su lectura.)

Las obras de restauración se apoyan siempre en grupos multidisciplinares que aportan diversas investigaciones desde diferentes disciplinas pero los estudios geométricos de esta índole no son corrientes fuera de las investigaciones académicas. Estos estudios pueden aportar documentación relevante para poner en valor el elemento patrimonial. 


\section{Metodología empleada}

Para la medición de la bóveda de crucería se ha empleado instrumentación de última generación, que permite una toma de datos muy precisa. Se ha utilizado estación total láser Leica TCR805ultra. La campaña de medición se desarrolló a los largo de dos semanas, durante julio de 2011, con un total de 21.946 puntos medidos. De esta forma se definieron sus deformaciones, su despiece y su geometría. El error máximo en la unión de los diferentes días de medición es de 4,8 milímetros [Figura 2].

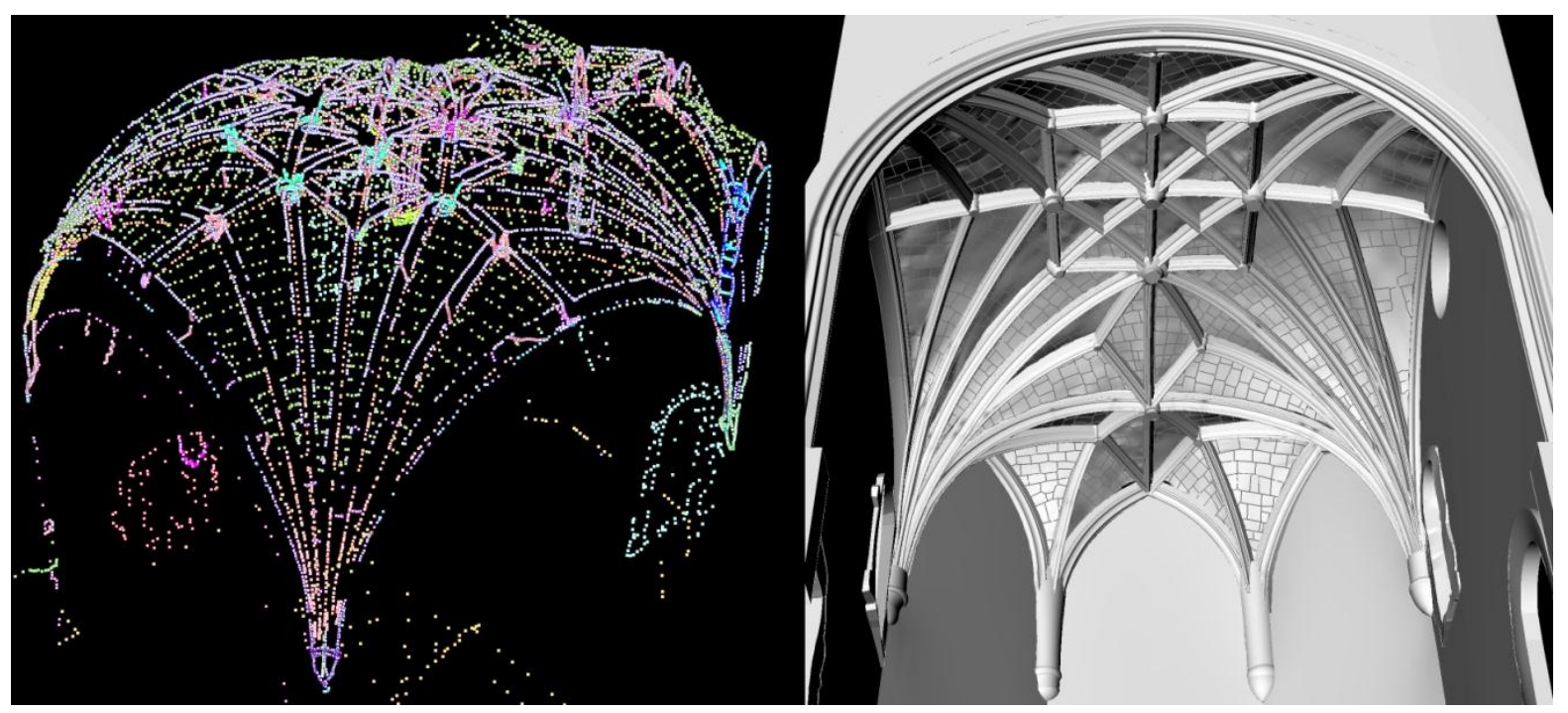

Figura 2. Nube de puntos y modelo 3D elaborados.

\section{La escuela de Toledo}

A mediados del siglo XV la Península Ibérica entró en contacto con el gótico que se estaba haciendo más allá de Francia, importándose técnicas, maestros canteros y arquitectos centroeuropeos. En Castilla se detectan dos focos de renovación del gótico distintos: el burgalés y el toledano. El diseño de la bóveda de Manzanares encuadra su construcción dentro de la escuela toledana. Sus combados son rectos, característica diferenciadora entre la escuela toledana y la burgalesa, que emplea nervios de proyección curva (Palacios 2009). Además el diseño de su traza es semejante al de algunas de las bóvedas de los principales representantes de esta corriente.

\section{Diseño de las trazas de la bóveda: Proporción, tramas y geometría}

En la época medieval se desarrollan dos sistemas reguladores: "ad triangulum" basado en el triángulo y "Ad cuadratum" basado en el rectángulo. En España, al menos en las plantas, solo se ha detectado el uso de la proporción basada en rectángulos. Otra herramienta de diseño interesante es la modulación, basada en el conocimiento de la Antigüedad sobre los números armónicos. Las más utilizadas en nuestro país corresponden al manuscrito de Simón García (Palacios 2009: 85). 
Se ha analizado la bóveda según estos parámetros. Su proporción es rectangular si tenemos en cuenta el tramo poligonal de la cabecera. Se trata de la proporción sexquitercia, es decir 4:3, la más utilizada en el gótico tardío. El triángulo de Pitágoras es el único con los tres lados formados por números enteros, 3, 4 y 5 unidades. Para conseguir este rectángulo solo hace falta colocar los dos triángulos rectángulos compartiendo su diagonal [Figura 3]. Esta proporción permitía el uso de la cuerda de 11 nudos para el replanteo (Palacios 2009). Al abatir el lado corto del rectángulo sobre su lado largo, conseguimos la posición del arco perpiaño que separa el tramo cuadrado de la cabecera poligonal.

Los diseños de las crucerías de las bóvedas góticas se dividen en dos grupos: las bóvedas estrelladas, con su diseño centralizado, como la bóveda que nos ocupa, y las bóvedas en red. Las bóvedas españolas organizan sus diseños según la posición del tercelete y con la ayuda de tramas ortogonales como elemento regulador, que permiten fragmentar la bóveda y colocar las claves en puntos estratégicos (Palacios 2009).

Para analizar el diseño de la bóveda de Manzanares [Figura 3] comenzamos con su tramo cuadrado. Una trama $5 \times 5$ junto con los ejes principales de la bóveda, permiten determinar la posición de las claves principales en el centro del conjunto. Uniendo los extremos de los rampantes obtenemos un cuadrado inscrito girado $45^{\circ}$ respecto a los ejes. El círculo inscrito en este cuadrado define, en su intersección con los rampantes, la posición del resto de las claves de este tramo. Solamente faltan dos claves en el lado Este, donde no se cumple la simetría. Estas se definen en la intersección de los terceletes con el cuadrado girado.
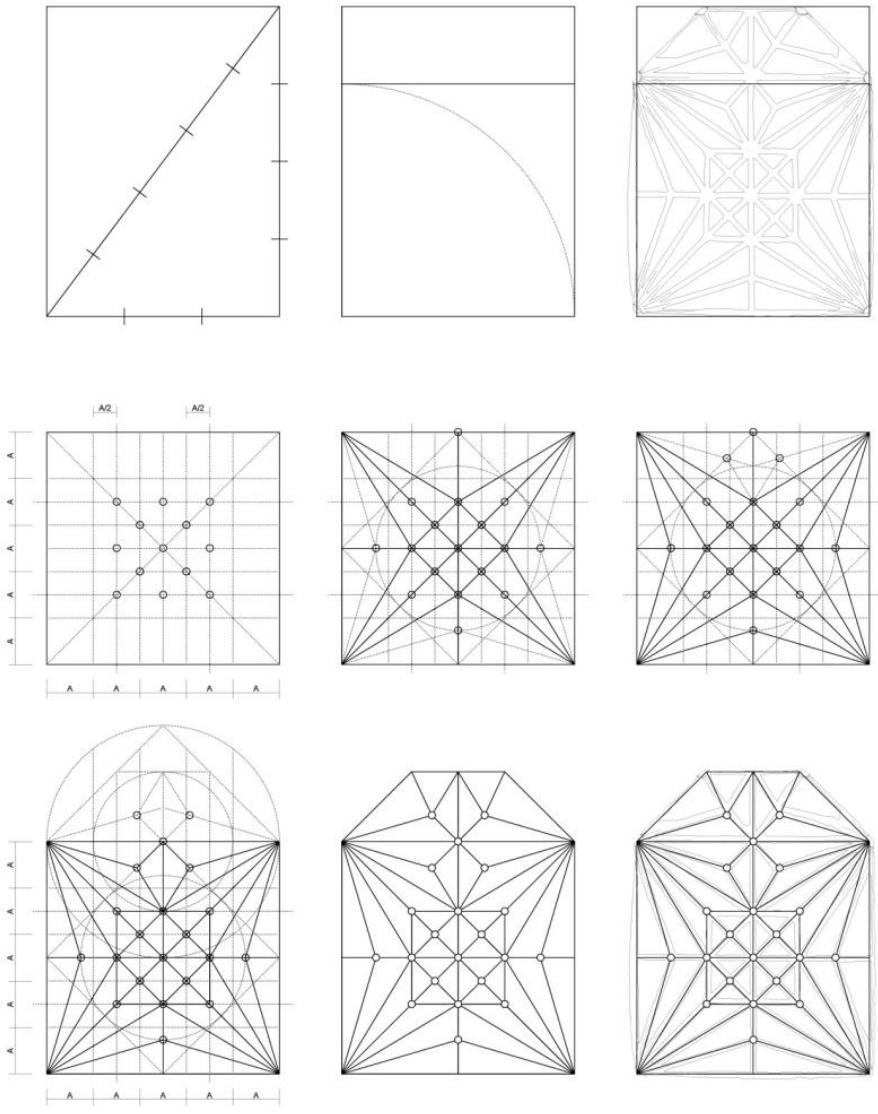

Figura 3. Proporción y geometría de su traza. Comparación con los datos medidos. 
En este momento ya se pueden situar las claves del tramo poligonal de la cabecera con una simple simetría tomando como eje el arco perpiaño. Solo faltan por definir los tres lados que cierran el presbiterio al Este. Teniendo el lado central de la cabecera triconque, los lados laterales se obtienen al trasladar el cuadrado girado.

Comparando esta traza con los datos obtenidos de la estación, vemos que encaja perfectamente sobre la planta, con ligeros desplazamientos en la zona poligonal que podrían deberse a fallos en el replanteo o deformaciones posteriores [Figura 3].

\section{El control de la forma y la estandarización de la construcción}

Hasta el siglo XV, las bóvedas góticas españolas se limitan al cruce de dos nervios diagonales. Su forma es el resultado más o menos controlado de la curvatura que tienen estos nervios. A partir del siglo XV, las bóvedas góticas multiplican sus nervios. La concepción es completamente distinta ya que primero se escoge la forma de la bóveda y luego se obliga a que cada uno de esos nervios tenga la curvatura necesaria para conseguirla. Para ello se necesitó un profundo conocimiento de geometría (Palacios 2009).

La multiplicación de los nervios contribuye a la elasticidad de la construcción y facilita además el proceso de montaje ${ }^{7}$. Por otro lado puede complicar enormemente su proceso constructivo. Para evitarlo sus nervios se diseñan mediante técnicas de estandarización que permiten construir la bóveda con el menor número de arcos distintos. Se intenta conseguir el mayor grado de complejidad de la forma más sencilla posible. Estas técnicas son distintas en cada país ${ }^{8}$.

\section{La montea de la bóveda de Manzanares}

Para conseguir la montea de una bóveda hay que desarrollar un proceso previo mediante un método de proyección, hoy ya plenamente conformado y conocido como sistema diédrico. Este sistema permite determinar la elevación de una bóveda coordinándola con su planta. Solo las elites del gremio de cantería, poseían estos conocimientos (Palacios 2009).

La montea se definía a tamaño real en las "salas de trazas", habilitadas en obra con sus paredes y suelos enlucidos con yeso (Gómez 1998). Allí se tallaban cada una de las dovelas de los nervios de acuerdo con la curvatura definida previamente por el arquitecto.

Para determinar la montea hay que concretar previamente la línea de imposta. En Manzanares las jarjas han sufrido diversas transformaciones a lo largo de los años, por lo que no se podía asegurar su posición. Para definirla se han comparado las curvaturas de formeros, perpiaños y ojivos porque sus centros suelen situarse sobre ella. Efectivamente, todos coinciden, salvando las deformaciones que presenta la bóveda, en una línea de imposta ficticia que se encuentra justo donde empiezan las molduras de los nervios en los tambores de arranque, es decir, por encima de las ménsulas. Sobre esta base se empezaron a analizar las curvaturas de cada nervio ${ }^{9}$ [Figura 4]:

\section{- $\quad$ Rampantes:}

La bóveda es de rampante redondo rebajada. Las ligaduras tienen una curvatura muy poco pronunciada. Son arcos de círculo con su centro muy por debajo de la línea de imposta. Por tanto sus claves tienen elevaciones diferentes por lo que cada nervio llega a una altura distinta. Ambos rampantes, longitudinal y trasversal, son distintos entre sí. El primero baja 16 centímetros más, en su unión con el perpiaño Este. 
- Combados:

Parece haber una relación entre la curvatura de los rampantes y la de todos los combados, excepto los que se encuentran girados $45^{\circ}$ en torno a la clave central.

Los combados que forman un cuadrado alrededor de la clave central y que tienen su posición paralela al rampante longitudinal, comparten su misma curvatura. Los paralelos al rampante transversal la comparten con éste último. Los demás tienen la curvatura del rampante longitudinal.

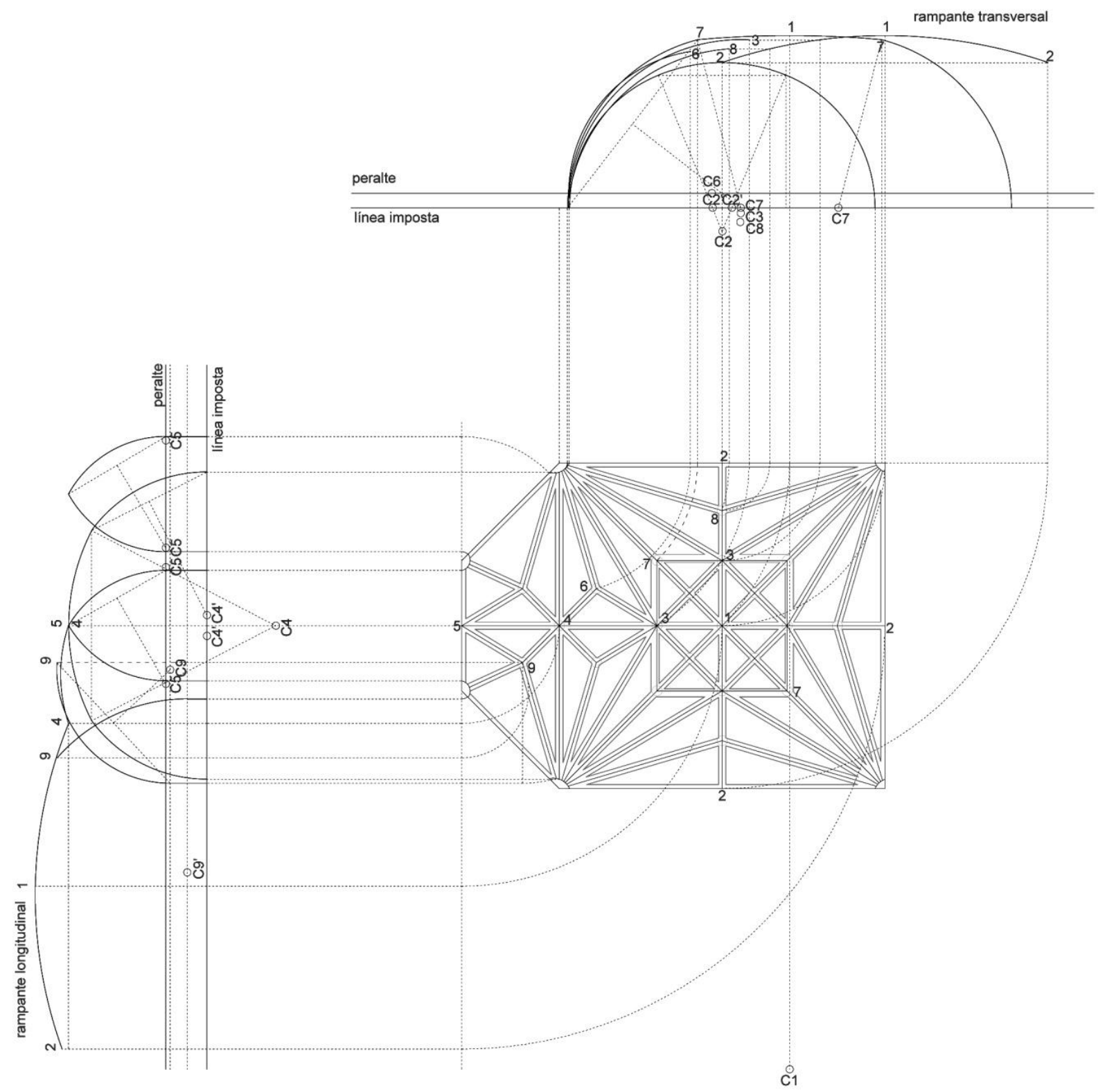

Figura 4: La montea. 
- $\quad$ Formeros y perpiaños:

En el tramo cuadrado de la bóveda, los arcos formeros y perpiaños son arcos ovales o carpaneles, es decir, arcos de tres centros. Los dos formeros y el perpiaño que da a la nave central de la iglesia, son iguales entre $\mathrm{sí}^{10}$ (próximos al medio punto, solo bajan 0,19 metros). Se ha definido el punto de intersección entre las tres curvaturas a 1/12 de la altura que alcanzan los arcos.

El arco perpiaño que separa el tramo cuadrado de la bóveda de su cabecera poligonal, es también un arco oval. Este arco es más rebajado que los tres anteriores (0,36 metros respecto del medio punto). El punto de inflexión entre las curvaturas del arco oval se ha definido a 1/6 de la altura total.

Al comparar los cuatro se puede observar que son arcos ovales que comparten sus curvaturas inferiores, no la superior. Los combados, en forma de cuadrado girado $45^{\circ}$ en torno a la clave central, tienen la misma curvatura que el tramo superior del arco oval de los formeros.

Los tres arcos formeros de la cabecera poligonal son arcos apuntados peraltados 1 metro sobre la línea de imposta. Tienen sus centros sobre la línea de peralte, prácticamente en el punto donde arranca el arco simétrico a ellos. La luz del arco central es $10 \mathrm{~cm}$ menor que la de los otros dos.

- Ojivos:

Los arcos diagonales son también arcos ovales (bajan 1,20 metros desde el medio punto). Tienen dos de sus centros en la línea de imposta y el otro 20,94 metros por debajo de esta. Su forma es muy plana en la zona superior. Las intersecciones entre las dos curvaturas se producen en las claves secundarias del ojivo.

- $\quad$ Terceletes:

Comparten la misma curvatura que el arco inferior de los nervios diagonales. El recurso de estandarización utilizado concretará la autoría de la bóveda, y lo veremos detenidamente más adelante.

Solo los terceletes situados más cerca del perímetro de la bóveda que se unen con el rampante longitudinal, cuatro en total, tienen su curvatura distinta. Están peraltados 0.36 metros sobre la línea de imposta. Su curvatura coincide con los arcos inferiores de los óvalos de formeros y perpiaños.

- $\quad$ Nervios de la cabecera trebolada:

Hay cuatro arcos que arrancan de las jarjas hacia las claves. Los dos que salen de las jarjas con mayor número de nervios, tienen un peralte de $90 \mathrm{~cm}$ y su curvatura es la del arco formero apuntado central.

Los otros dos arcos, que salen de las jarjas sencillas de tres nervios, están peraltados $48 \mathrm{~cm}$ sobre la línea de imposta y su curvatura es la de los arcos inferiores de los ojivos.

\section{Estandarización inglesa. Autoría de la bóveda}

En España se utilizaba por norma la estandarización francesa. No se ha detectado la utilización de la estandarización inglesa en ningún arquitecto español a excepción de Juan Guas (Palacios 2009). El arquitecto bretón ha utilizado este recurso en las bóvedas del Convento de Santa Cruz en Segovia y en el claustro de la Catedral de Segovia (Palacios 2009). Por tanto, el análisis del tipo de estandarización utilizada en Manzanares puede aportar conclusiones interesantes sobre la autoría de la bóveda. 
Juan Guas no utiliza este mecanismo en todas sus bóvedas, pero es el único arquitecto que lo ha utilizado en nuestro país. Si no se detectase este recurso no se podría descartar su autoría. En cambio si es esta la estandarización utilizada, la autoría de Juan Guas se podría confirmar.

La estandarización inglesa utiliza la misma curvatura en ojivos y terceletes. Como cada arco debe alcanzar elevaciones distintas, se giran desde el arranque hacia delante o hacia atrás para conseguir la altura deseada ${ }^{11}$. Este recurso se puede percibir visualmente ${ }^{12}$, ya que al tener los arcos sus centros por debajo o por encima de la línea de imposta no son perpendiculares a la vertical en su arranque $^{13}$.

En Manzanares todos los terceletes, excepto cuatro, tienen la misma curvatura que el tramo inferior del arco oval de los ojivos. La estandarización se realiza girando este arco hacia delante para alcanzar la altura a la que llega cada nervio. El arquitecto ha utilizado la estandarización inglesa. Se confirma así la autoría de Juan Guas [Figura 5].
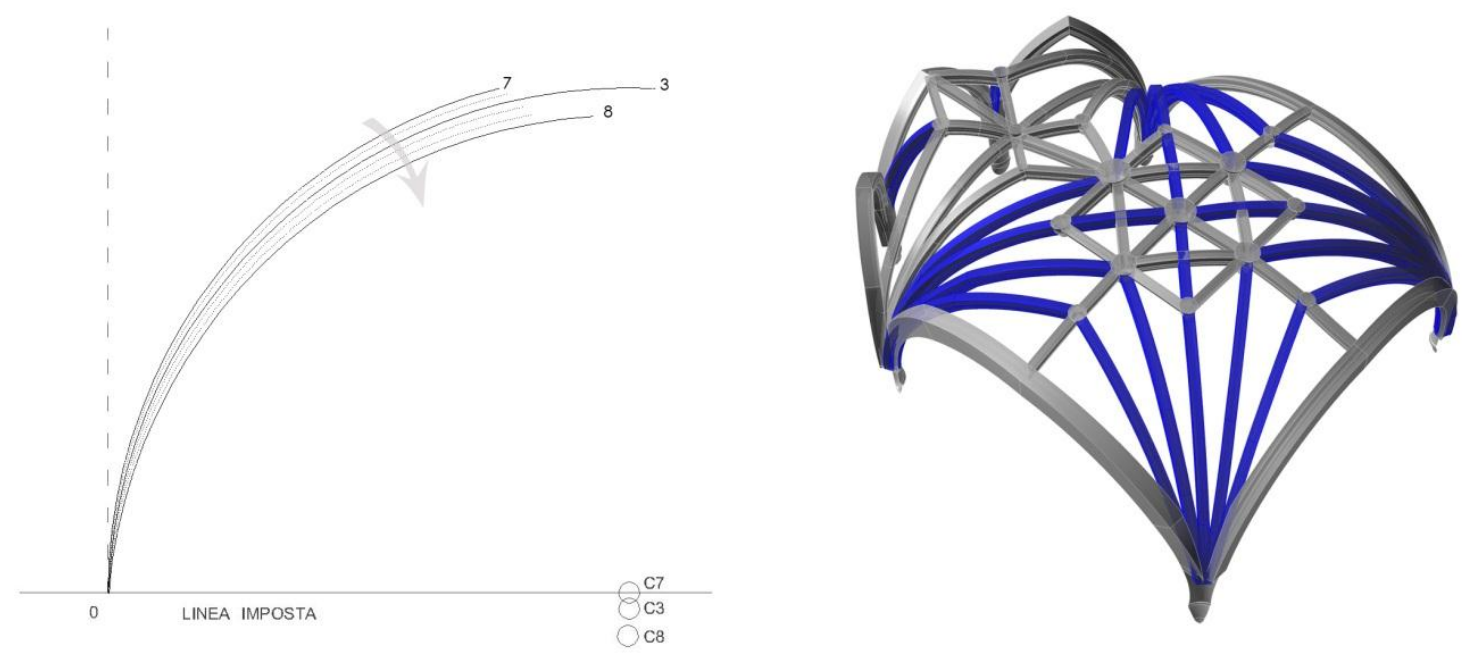

Figura 5. Curvaturas de ojivos (7) y terceletes (3 y 8): Estandarización inglesa (nervios en color azul).

\section{Otros detalles que apoyan la autoría de Juan Guas}

El arquitecto bretón aplica en varias ocasiones tendencias francesas en la construcción de sus bóvedas. (Gómez 1998). Algunas de ellas podemos encontrarlas en Manzanares.

Los nervios de la bóveda que nos ocupa tienen formas escultóricas que proyectan sombras. Las bóvedas con esta capacidad plástica aparecen en el siglo XV en España de la mano de maestros borgoñones, flamencos y alemanes. Como entalladores aportaron al corte de los nervios gran plasticidad escultórica, como si las labores de talla en madera se hubieran trasladado a la labra de piedra. Este recurso se desarrolla en los focos levantino y toledano. Guas es un buen ejemplo de ello (Gómez 1998). 
Las molduras de los nervios presentan reposiciones de yeso de distintas épocas. Estas reintegraciones parecen indicar que se ha ido rellenando una moldura cóncava original que ocultaba la unión entre los nervios y la plementería. Con esta sección los nervios arrojarían sombra sobre la plementería provocando el engaño visual típico del flamboyante francés, que podemos ver en Saint Gervais de París (Palacios 2009) [Figura 6]. Parece que la plementería vuela por encima de los nervios sin tocarlos. Este recurso formal francés no ha sido detectado en los arquitectos españoles a excepción de Juan Guas, como vemos en las bóvedas del claustro de la Catedral de Segovia [Figura 10].

Existe también una modalidad de claves muy difundida en Francia, de la que apenas hay muestras en España. Son claves con nervios pinjantes que desarrollan su volumen hacia el intradós. La única bóveda española que se conoce con esta fórmula fue construida por Juan Guas para cubrir el ángulo sureste del claustro de la catedral de Segovia. Los nervios cruceros se descuelgan, sin llegar a apartase de la plementería en el polo de la bóveda, arrastrando consigo a la clave mayor (Gómez 1998: 154). En Manzanares, al fijarnos detenidamente en la clave del perpiaño que separa los tramos cuadrado y poligonal de la bóveda, vemos que su forma se alarga hacia abajo tímidamente. Los nervios la acompañan en su descenso, alejándose en ese punto de su geometría oval [Figura 6]. Esta plasticidad recuerda la clave pinjante de Guas en Segovia.
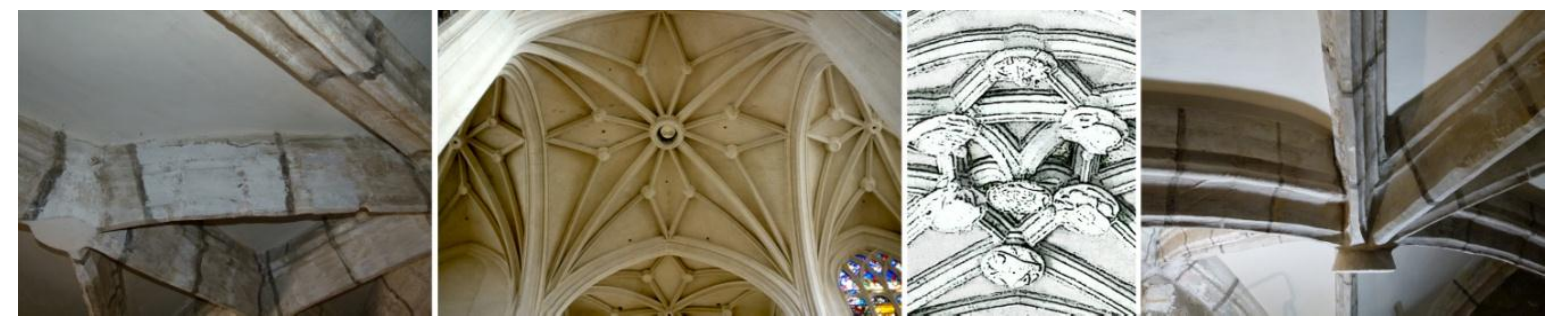

Figura 6. Reposiciones en los nervios de Manzanares; bóvedas de Saint Gervais de París (foto de José Carlos Palacios); clave pinjante en la catedral de Segovia (Roberto Fernández Díaz) y en Manzanares.

\section{Talla de las piezas}

Vamos a abordar el análisis de los cuatro elementos que configuran la bóveda: nervios, claves, jarjas y plementería:

\section{- Los nervios:}

En esta bóveda se dan los dos tipos de nervios que encontramos en el gótico: de molde cuadrado, orientados hacia el centro de la bóveda o situados sobre sus ejes principales; y de molde revirado, con su eje en vertical pero reajustando la moldura de una retícula cuadrada a una retícula oblicua (Rabasa 2000) ${ }^{14}$.

En este caso los nervios de molde cuadrado son los ojivos, los rampantes y los combados que describen los dos cuadrados en torno a la clave central. De molde revirado son los demás combados, todos los terceletes y los nervios de la cabecera triconque [Figura 7].

Con respecto al diseño de molduras en los nervios, hay dos tipos de secciones en Manzanares que corresponden a una jerarquía: los perfiles con molduras más pronunciadas, que se encuentran en los nervios de mayor importancia constructiva, ojivos, perpiaño, formeros y los terceletes que están 
a cada lado de los diagonales; y los nervios de segundo orden, que serían los que presentan el perfil de molduras más suaves, los terceletes situados en el perímetro de la bóveda, los rampantes, todos los nervios de la cabecera trebolada y todos los combados restantes ${ }^{15}$.

Las dovelas de los nervios son de yeso ${ }^{16}$ y tienen una longitud de entre 30 y 40 centímetros. Solo varían de tamaño en las zonas superiores de cada nervio, donde se requiere trabajo in situ para encajar las últimas piezas antes de sus encuentros con las claves. El yeso es muy blando y permite una talla muy rápida. Después de estudiar el contexto y el elemento, pensamos que se emplearía una técnica mixta ${ }^{17}$, aprovechando las ventajas de la talla y la formación de piezas con molde.

Al no haber talleres de yeso en la zona, y no ser una técnica utilizada en Madrid, probablemente se encargaron las piezas prismáticas a un taller operativo lejos de Manzanares. El transporte siempre acarrea golpes y deformaciones. Posteriormente se terminaban en obra, con ayuda del baivel y la saltarregla, igual que en cualquier obra tradicional de cantería [Figura 7].


NERVIOS DE MOLDE CUADRADO

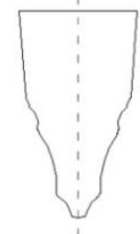
Rampantes y
combados cen

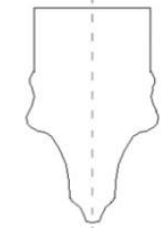

Ojivos
Este

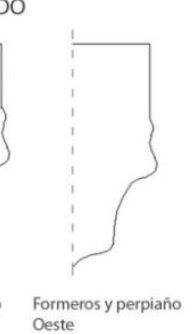

NERVIOS DE MOLDE REVIRADO
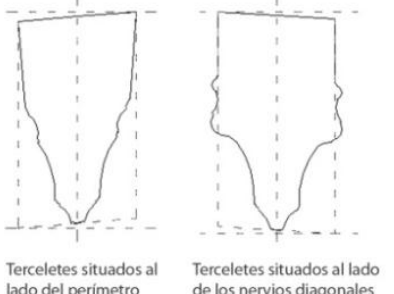

Terceletes situados al lado
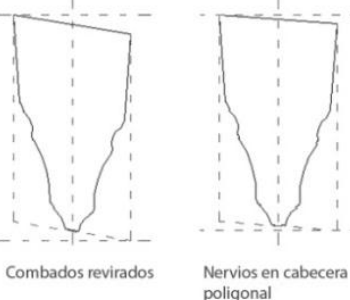

poligonal

Figura 7. Arriba talla de una dovela de los ojivos (molde cuadrado), dibujos realizados por Roberto Fernández Díaz. Abajo secciones de cada nervio de la bóveda.

- Las claves.

Por la complejidad que conlleva su talla, las claves las hacían un grupo especializado de canteros. En Manzanares encontramos los dos tipos de claves que se dan en las bóvedas del gótico tardío: son las de molde revirado, que tienen el eje del cilindro en vertical; y las de molde cuadrado, es decir, orientadas hacia el centro de la bóveda por lo que su eje es perpendicular a la superficie de plementería.

El proceso de talla para cada tipo de clave es distinto [Figura 8]. Las de molde revirado se tallan desde su trasdós. Partiendo de un prisma con superficie plana, se dibuja la planta en su trasdós. Se tallan las caras inclinadas donde acaban los brazos de la clave, llevando el ángulo con la saltarregla con respecto a la cara superior. Se colocan las plantillas en las caras inclinadas y se van labrado con 
ellas los nervios y al mismo tiempo el cilindro central hasta que se van encontrando (Palacios 2009; Rabasa 2000).

Las de molde cuadrado se tallan desde su cara de intradós (Palacios 2009; Rabasa 2000). Se saca la plantilla en verdadera magnitud de esta cara y a partir de ella se talla la pieza, avanzando hacia el trasdós. Se le dará la inclinación correspondiente a los planos donde acaban los brazos de la clave. Posteriormente con las plantillas se moldean las secciones de los nervios.

En Manzanares hay solo dos claves con eje vertical, la clave polar y la del perpiaño Este. Esta última es una esplendida clave pinjante, con desarrollo hacia el intradós. El resto de las claves son de molde cuadrado ${ }^{18}$, con sus ejes girados hacia el centro de la bóveda. Se han encontrado restos de pintura decorativa en sus torteras. Los brazos suelen ser de escasa longitud para evitar errores. En Manzanares algunos prácticamente no existen, y otros en cambio llegan a tener más de 15 centímetros. Probablemente el conjunto se ha retocado in situ. Algunas de ellas tienen refuerzos metálicos, clavos de forja, para unirlas a la plementería.

TALLA DE CLAVES DE MOLDE CUADRADO
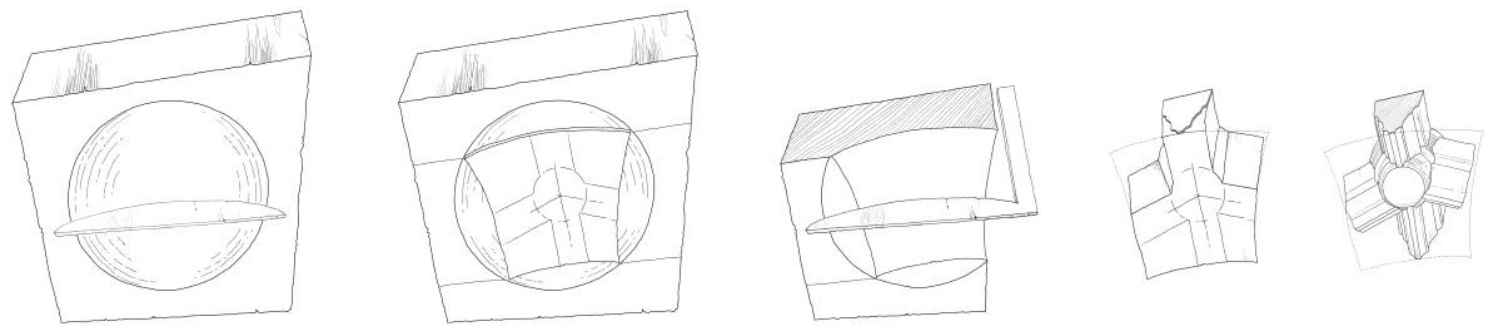

TALLA DE CLAVES CON EJE VERTICAL
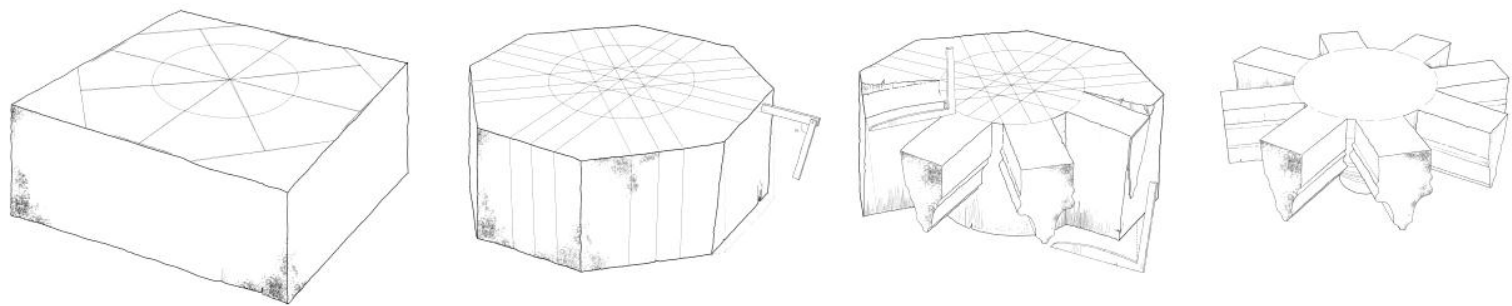

Figura 8: Arriba: talla de una de las claves pequeñas (de molde cuadrado). Abajo: talla de la clave central (con el eje vertical). Realizados por Roberto Fernández Díaz.

- Las jarjas.

Los enjarjes o arranques de los nervios, suelen ser las piezas más complejas de la bóveda junto con las claves. Aquí en cambio, se han simplificado notablemente.

Normalmente los jarjamentos son piezas superpuestas: cada una engloba todo el haz de nervios, con sus molduras, secciones e inclinaciones diferentes, lo que complica enormemente su talla.

Esta bóveda ha sufrido reintegraciones importantes en sus jarjas, especialmente en las ménsulas inferiores, que han variado mucho de tamaño y geometría. 
Encontramos tres tipos de jarjas distintas que se repiten por la simetría del conjunto ${ }^{19}$. Dos de ellas recogen nueve y siete nervios respectivamente, y se han construido de la misma manera. La otra es más sencilla, solo llegan a ella tres nervios [Figura 9].

Las tres se apoyan sobre una ménsula en forma de medio capitel de yeso y cal. Las reintegraciones sobre la pieza original llegaban a tener 6 centímetros. Al eliminarlas se han encontrado restos de diversos pigmentos y varias etapas distintas. La forma original parece haber sido un escudo en medio relieve que se sustituyó por formas geométricas simples de menor calidad. Esta pieza terminaba en una moldura cóncava superior, de menor tamaño que las que encontramos ahora ${ }^{20}$. Encima había una junta de mortero donde apoyaban las piezas del enjarje.

Las jarjas de múltiples nervios tienen dos piezas lisas de cal o trabadillo en forma de tambor realizadas en taller, con la decoración de yeso superpuesta in situ y trabajada continuando la forma de las molduras de cada nervio. Esta decoración presenta huella de gradina, además se falsean cajeados en su perímetro, todo ello con la intención de que pareciese piedra tallada.

Sobre ellas encontramos las dos únicas piezas complejas del conjunto, talladas en la sala de trazas con dos plantillas, la de la cara superior y la de la cara inferior, como los jarjamentos de cantería ${ }^{21}$. La cara superior de la última de estas piezas ya no es horizontal, presenta la inclinación necesaria para recibir a los nervios. Encima de ella se colocan las dovelas de cada nervio y se unen entre sí, con retoques in situ para dar continuidad en las zonas de intersección entre ellas y simular una sola pieza ${ }^{22}$. En las sucesivas la separación entre piezas es visible, y va apareciendo la plementería por detrás.

Las jarjas de tres nervios son simples tambores superpuestos sobre la ménsula-escudo, cuatro en total. El último tambor se une in situ con las dovelas de los arcos que le llegan, retocándolas para parecer molduras pertenecientes a la pieza. Los dos tambores inmediatamente inferiores presentan molduras de yeso realizadas in situ para dar continuidad a las anteriores. Los primeros tambores de la jarja tienen diversas fracturas.
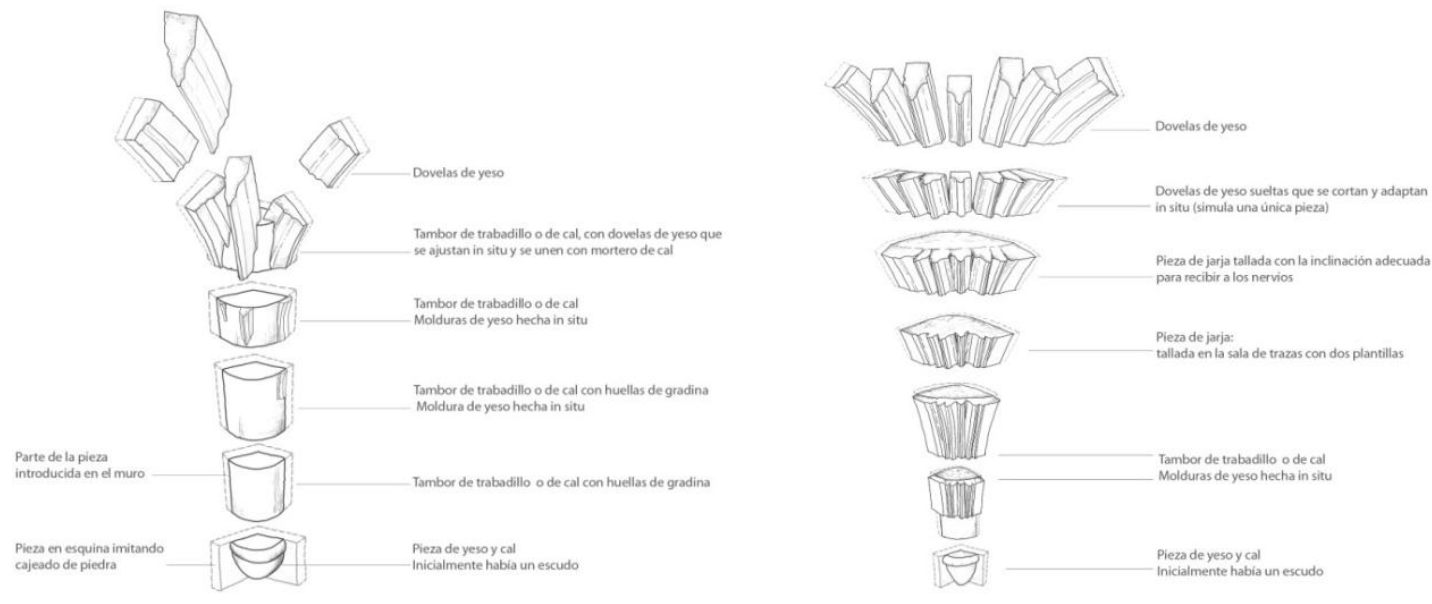

Figura 9. Construcción de las jarjas simples (de tres nervios) y complejas (de siete). Dibujos realizados por Roberto Fernández Díaz. 
La plementería:

Es la superficie cóncava que da forma a la cascara de la bóveda. En este caso es tabicada de una sola vuelta, es decir, con ladrillos colocados de plano. Tienen un tamaño medio aproximado de 20 x30 centímetros ${ }^{23}$. En su montaje no se requiere de medios auxiliares, ya que se tienden entre nervios tres o cuatro ladrillos ligeros, unidos con mortero de yeso, por lo que fragua rápidamente. Al no tener que tallar los plementos, la construcción de la bóveda es muy rápida. Los rellenos en sus riñones cubren $2 / 3$ de la altura de la bóveda ${ }^{24}$.

El aparejo empleado es a la inglesa, ya que la plementería sale de las jarjas en hiladas horizontales apoyándose en los nervios. Su disposición gira en torno al eje vertical formando las famosas trompetas inglesas. Al ir avanzando dejará una zona en la parte superior en forma de estrella, que se ha resuelto disponiendo los plementos de otra manera, más o menos desordenada, para cerrar la superficie [www.enjarje.com/levantamientos/manzanares.html].

La plementería nos indica cómo se ejecutó la bóveda. Las hiladas de despiece, la mayor parte de las veces, no tienen continuidad en el plemento siguiente. Esto quiere decir que la bóveda no se ha ejecutado como una tabicada, construyendo previamente la cascara de ladrillo y luego colocando los nervios, sino como las bóvedas de piedra. Los nervios son cimbras durante la ejecución, que luego permanecen. En este caso sirven fundamentalmente, por su escasa resistencia, como control de la forma de la bóveda. Estas plementerías se revocaban, ocultando su factura de ladrillo.

\section{Forma de la bóveda y deformaciones detectadas}

La cota más alta de la bóveda no es la clave central sino los combados que la rodean. Los rampantes redondos le confieren una volumetría esférica rebajada por la escasa diferencia de cota entre los formeros y la clave central (0,60 metros). El empleo de arcos ovales, disminuye la altura de la bóveda y con ello la de los muros, lo que contribuye a un abaratamiento de la construcción.

Hay un desplome en la cabeza de los muros norte y sur del presbiterio, de 18 y 6 centímetros respectivamente.

\section{Proceso constructivo. Estructuras auxiliares}

Primero se construía la plataforma de trabajo, que se situaba a la altura donde terminan las jarjas. Ahí se realizaba con cal sobre los tablones de madera el diseño de la crucería de la bóveda. Se volteaban los arcos formeros y los perpiaños, a modo de tirantes para estabilizar los lienzos todavía inestables. Después se disponían las cimbras de los demás nervios y se determinaba con pies derechos la altura exacta de cada clave. Una vez hechos, se adintelaba la plementería sobre ellos (Palacios 2009; Gómez 1998) ${ }^{25}$ [www.enjarje.com/investigacion/manzanares.html].

La diferencia entre bóvedas de ladrillo con nervios de piedra o yeso puede reducir su coste a la mitad (Gómez 1998: 187). En una bóveda como la de Manzanares se ahorra tiempo, mano de obra cualificada y su manipulación es más sencilla.

\section{Estudio comparativo de la bóveda con otros ejemplos españoles}

La bóveda de Manzanares presenta similitudes con otros diseños de Juan Guas. En la bóveda del convento de Santa Cruz en Segovia, podemos ver uno de los diseños de traza en planta más fre- 
cuentes en la escuela toledana. Se trata del cuadrifolio dibujado con nervadura secundaria recta, formando cuatro hojas romboidales en forma de pica. En Manzanares lo encontramos en los combados de su lado Este. Este diseño lo repite en el convento de Santo Tomás de Ávila y algo modificado en el conventual de El Parral, en Segovia. En las jarjas de la bóveda de Santa Cruz se puede ver como los nervios no salen tangentes a la vertical. Según la montea estudiada por José Carlos Palacios también hay estandarización inglesa, al igual que en las bóvedas del claustro de la catedral de Segovia (Palacios 2009: 172).

El diseño central con dos cuadrados de combados, uno de ellos girado, concéntricos a la clave polar, lo podemos encontrar en las bóvedas de San Juan de Toledo de Juan Guas (Palacios 2009: 159). También en la capilla del Sagrario de la Catedral de León de su discípulo Juan de Badajoz el Viejo (Palacios 2009: 135)

En la bóveda central del atrio de la catedral de Oviedo, Juan de Badajoz el Viejo, repite el diseño de los combados junto con las hojas romboidales en forma de pica (Palacios 2009: 182) [Figura 10].
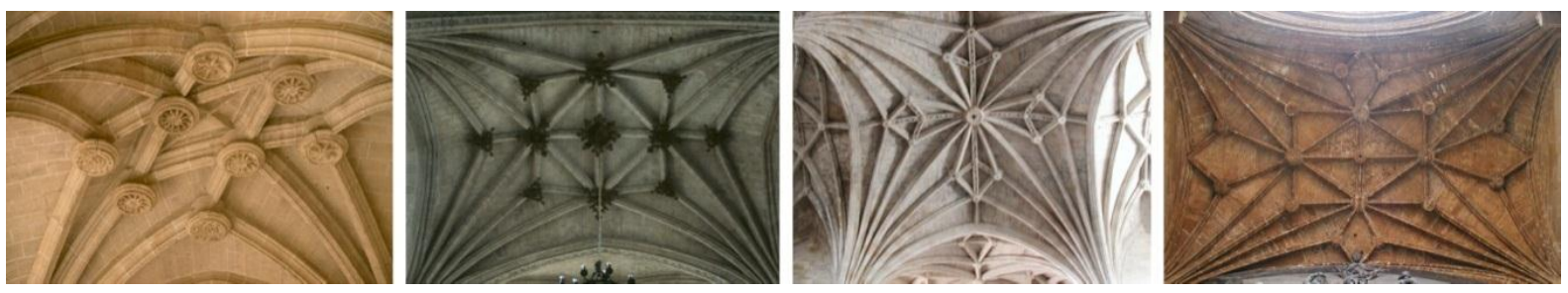

Figura 10. Bóveda de la Catedral de Segovia, nave de San Juan de los Reyes (Toledo), convento de Santa Cruz (Segovia) y bóveda central del atrio de la catedral de Oviedo (Fotografías de José Carlos Palacios).

Las bóvedas de Juan Guas son casi todas de cantería. Podemos encontrar un ejemplo de ladrillo realizado por el bretón pero muy distinto a Manzanares en la Cartuja del Paular (Madrid), donde hace las bóvedas de nervios de piedra y rosca de ladrillo.

\section{Conclusiones del estudio}

Las características formales de la bóveda apuntan hacia la escuela de Toledo. Después de estudiar su traza se concluye que tiene proporción sexquitercia y apoya su diseño en una trama de $5 \times 5$ que ayuda a posicionar las claves con sencillos procesos geométricos. El resultado final es un diseño muy utilizado por algunos de los mayores exponentes de la escuela de Toledo, y especialmente parecida a las obras de Juan Guas.

El análisis de su montea ha revelado que se trata de una bóveda realizada con arcos ovales, es decir, de tres centros, que le dan su aspecto rebajado. Se ha utilizado además la estandarización inglesa, recurso no utilizado en España con la excepción de Juan Guas, lo que nos confirma su autoría. Otros detalles, esta vez compositivos, parecen apuntar de nuevo al arquitecto bretón, como es su clave pinjante y la forma de las molduras de sus nervios, características importadas del gótico francés y solo utilizadas en España por Juan Guas.

La construcción de la bóveda fue muy rápida. Tabicada de una sola vuelta con aparejo a la inglesa, sus nervios son dovelas de yeso fabricadas con técnicas mixtas: mediante moldes y talladas posteriormente con baivel. Las claves fueron realizadas en taller. En las jarjas se emplearon de nuevo técnicas mixtas, realizando unas piezas en taller, y otras in situ. Su proceso de montaje es el mismo 
que para una bóveda de cantería, primero se colocan los nervios con cimbras y después se tiende la plementería encima.

Los materiales empleados son realmente sorprendentes en el momento y lugar de su construcción. Su talla está muy trabajada, especialmente en sus claves, así que no parece una construcción provisional. Podría ser el resultado de la urgencia en cerrar el presbiterio para algún evento social o político relevante, ya que el yeso se trabaja mucho más rápido que la piedra. Estos casos no son aislados en la historia de la construcción ${ }^{26}$. En todo caso esta hipótesis que se apunta no se ha podido corroborar con datos históricos o documentales.

\section{Agradecimientos}

A la Dirección facultativa, Antonio Ábalos y Juan López, por las facilidades aportadas para la realización de este trabajo. Igualmente a la empresa constructora Mármoles y Granitos Cabanillas, especialmente a su restauradora Carla Olivé.

Mi agradecimiento a los dos organismos promotores de la obra, el Arzobispado de Madrid y la Dirección General de Patrimonio Histórico de la Comunidad de Madrid, especialmente a Luis Serrano Muñoz, jefe de área de conservación y restauración, y José Juste Ballesta, técnico arquitecto de la Dirección General.

Hacer mención especial al arquitecto José Carlos Palacios Gonzalo, director de mi tesis doctoral, por su inestimable ayuda en mi conocimiento de las bóvedas de crucería y por sus consejos para realizar esta investigación.

\section{Glosario}

Arco oval o carpanel: arco formado por tres centros. Está compuesto de dos arcos de circunferencia situados en sus extremos con su centro en la línea de imposta, unidos con un arco superior, más tendido, con su centro situado por debajo de la línea de imposta.

Baivel: es una escuadra de brazos no articulados, uno recto que se orienta hacia el centro geométrico del arco y otro curvo que reproduce la curvatura del arco. Cada arco tiene su propio baivel, que se hace a partir de la montea.

Cercha: Tabla curva que servía para comprobar la labra de una dovela. .

Enjarje, jarja o jarjamento: Arranque común de los nervios de una bóveda de crucería. Los nervios en esta zona, desde que nacen hasta que se separan, son molduras de un mismo sillar.

Montea o traza de la bóveda: trazado del despiece y los detalles de una bóveda a tamaño natural, para la obtención de plantillas. Se trazaba en el suelo o en la pared.

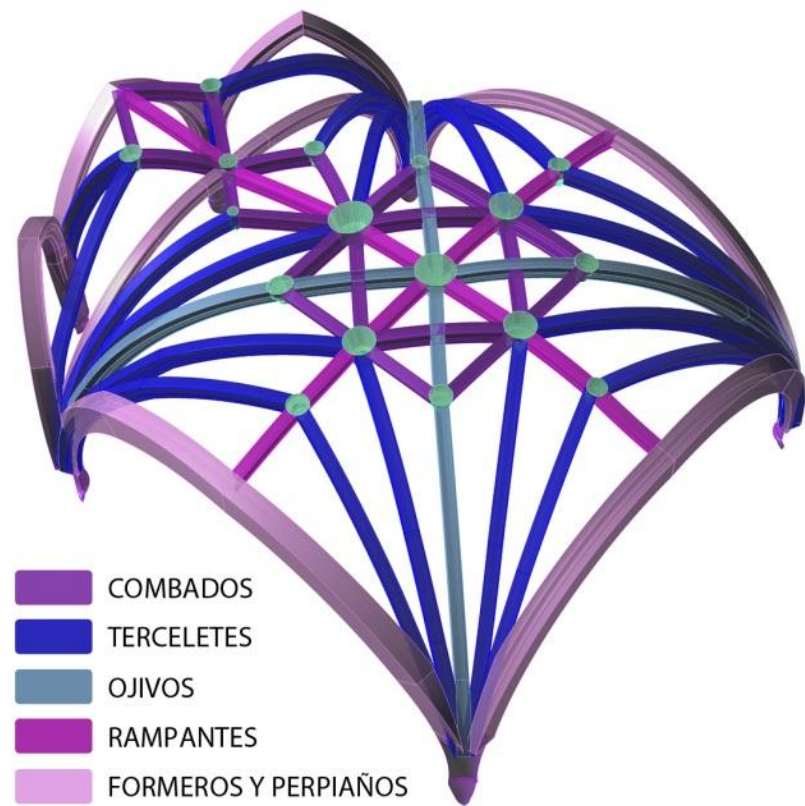

Figura 11. Tipos de nervios 
Saltarregla: es una escuadra articulada que permite tallar los ángulos.

Tipos de nervios (Figura 11): nervio perpiaño, nervio ojivo, diagonal o crucero, nervio tercelete, nervio combado, nervio de ligadura o rampante, nervio formero.

\section{Notas}

[1] El estudio de paramentos fue realizado por el Estudio de Arqueología y Patrimonio GROMA, en marzo de 2010. El estudio histórico-artístico fue realizado por Antonio Marchamalo Sánchez y Miguel Marchamalo Maín en abril de 2011. Debido a la ausencia de fuentes documentales directas, se utilizó el método deductivo a través de la recapitulación histórica basada en criterios cronológicos y estilísticos, para poder aproximar las fechas de construcción y la autoría de la bóveda.

[2] Juan Guas y Enrique Egas trabajaron para el cardenal Pedro González de Mendoza cubriendo los pies de la nave central de la catedral de Toledo en 1493. Ambos arquitectos y su equipo de alarifes trabajaron en las obras más importantes de la familia Mendoza en el último cuarto del siglo XV..

[3] Se tomaron cinco muestras en distintas partes de la bóveda: en el mortero de extradós, en el mortero de intradós de rejuntado de la plementería, en el mortero de los nervios, en el mortero del rejuntado del paramento de sillarejo de la cabecera y en el mortero de unión de las jarjas a los muros.

[4] Estos ensayos fueron realizados por el laboratorio Arte-Lab S.L. Los resultados de este estudio han sido facilitados por la empresa constructora encargada de las obras de restauración, Mármoles y Granitos Cabanillas.

[5] Las muestras tomadas se encontraban ocultas entre los nervios y la capa de yeso del trasdós de la bóveda, ya que no deben de haber estado expuestas a la luz porque podría distorsionar los resultados obtenidos.

[6] Los resultados de este estudio han sido facilitados por la empresa constructora encargada de las obras de restauración, Mármoles y Granitos Cabanillas, que solicitó el estudio al laboratorio mencionado.

[7] Los nervios están tan próximos que se pueden adintelar los plementos prescindiendo de estructura auxiliar.

[8] La estandarización francesa traza todos sus arcos a partir de la curvatura de la semicircunferencia con sus centros en la línea de imposta. En la estandarización inglesa un mismo arco se inclina hacia delante y hacia atrás para definir todos los nervios. En el modelo alemán un solo arco da forma a la totalidad de la bóveda (Palacios 2009, 57-67)

[9] Este estudio se ha realizado con las curvaturas del intradós de los nervios. En la montea se dibujan las curvaturas atendiendo a su intradós aunque a veces se hace con el trasdós. La elección de uno u otro depende de hacia dónde se enrasen los nervios en el jarjamento. (Palacios 2009).

[10] El formero norte presenta un añadido de yeso de una restauración posterior y tiene su curvatura distorsionada en la zona superior. No se tuvo en cuenta en la investigación de la montea.

[11] La estandarización inglesa evolucionará hacia métodos de simplificación a partir del uso de arcos ovales (Palacios 2009).

[12] Las jarjas de la bóveda han sido modificadas en restauraciones posteriores. Por eso es necesario recurrir a un estudio pormenorizado para verificarlo. 
[13] Juan Guas solo utiliza arcos inclinados hacia delante (no hacia atrás), es decir, con sus centros por debajo de la línea de imposta (Palacios 2009).

[14] Así se evitan los problemas de desacuerdos en la unión entre un nervio que asciende con otro horizontal. Además se adapta su trasdós a la curvatura de la bóveda.

[15] En el tratado de Simón García, Rodrigo Gil de Hontañón aplica una jerarquía a los nervios (Palacios 2009; Gómez 1998).

[16] Con tres capas: yeso grueso, yeso medio y acabado de escayola con las juntas pintadas. Éstas van casi a hueso, con mortero de yeso y cal.

[17] Si pensamos en un sistema de simplificación solo a base de moldes, saldrían 17 distintos. Se ha descartado esta opción porque al comparar los nervios que tienen igual sección y los que tienen igual curvatura, vemos como el arquitecto no hace coincidir ambos parámetros para optimizar el proceso de construcción por moldes (saldrían 13 en total). Además las características de las piezas nos remiten a un proceso mixto y con retoques in situ.

[18] Las claves de mayor tamaño han sufrido reintegraciones posteriores que parecen intentos de verticalizar sus cilindros centrales. Se percibe aun que sus ejes no son verticales.

[19] Las jarjas del lado norte están muy modificadas. La situada al Noroeste, tiene un tambor liso de 80 centímetros que es una reposición posterior. La cata realizada ha revelado que se ha perdido el arranque original completamente. Este refuerzo podría ser coetáneo a los añadidos del formero Norte.

[20] Realizadas con restos de ladrillos y piedras con cal.

[21] En las jarjas de nueve nervios hay solo una pieza realizada en taller.

[22] Se detecta que no es una sola pieza porque en la cara superior tiene diferentes alturas en cada nervio.

[23] Las piezas de ladrillo tienen en algunos casos formas trapezoidales en los modelos realizados. Los ladrillos son rectangulares y del mismo tamaño, pero ha sido imposible medir las juntas de mortero entre las piezas, que en algunos casos son grandes e irregulares. Los ladrillos dibujados están absorbiendo esas irregularidades.

[24] La bóveda se midió estacionando en el altar. No fue posible medir su trasdós porque las condiciones del edificio lo impedían. Las catas hechas en la plementería revelaron que la bóveda era tabicada de una sola vuelta. Teniendo el despiece del intradós de esta superficie ya se tenían los datos del trasdós. Solo se ha tenido que hacer una interpretación del despiece, siguiendo la lógica constructiva, en las zonas de plementería bajo los nervios y claves.

[25] El dibujo de la construcción de una bóveda que propone Rodrigo Gil aborda como se realiza el proceso (Palacios 2009; Rabasa 2000; Gómez 1998).

[26] En las Huelgas Reales de Burgos sus bóvedas de ladrillo y yeso del claustro de San Fernando y sus sólidos capaces en ménsulas y capiteles, son el resultado de un abandono de las obras, seguido posteriormente por la urgencia de su terminación para servir de escenario funerario (Palomo 2007; Ruiz 2007). 


\section{Bibliografía}

AITKEN, M.J. (1985). Termoluminescence Dating. London: Academic Press.

AMADOR DE LOS RIOS, J. (1852). Vida y Obra del marqués de Santillana. Madrid: Espasa Calpe-Austral.

ARTEAGA Y FALGUERA, C. (1940). La Casa del Infantado, Cabeza de los Mendoza, Volúmenes I y II. Madrid: Duque del Infantado.

AZCÁRATE RISTORI, J.M (1958). La Arquitectura Gótica Toledana del siglo XV. Madrid: CSIC.

AZCÁRATE RISTORI, J.M. (1970). Inventario Artístico de la provincia de Madrid. Madrid: Dirección General de Bellas Artes.

BECHMANN, R. (1984). Les racines des Cathédrales. L'architecture gothique, expression des conditions du milieu. Paris: Payot.

DEL PULGAR, H. (1970) (1500). Los Claros Varones de España, Edición. Salvat.

DE SANTIAGO FERNÁNDEZ, J., DE FRANCISCO OLMOS, J.M. (2006). "La inscripción de la fachada del Palacio del Infantado de Guadalajara". En Documenta \& Instrumenta, 4: 131-150.

FITCHEN, J. (1981) (1961). The Construction of Gothic Cathedrals. A Study of Medieval Vault Erection. Chicago: The University of Chicago Press.

GÓMEZ MARTÍNEZ, J. (1998). El gótico español de la Edad Moderna: bóvedas de crucería. Valladolid: Secretariado de Publicaciones e Intercambio Científico, Universidad de Valladolid.

GÓMEZ LÓPEZ, C. (1991). "Los Alarifes en los oficios de la construcción (siglos XV-XVIII)". Espacio, Tiempo y Forma, Serie VII, Historia del Arte, t. 4, Revista de la Facultad de Geografía e Historia de la U.N.E.D: 39-52.

GROMA (2010). Informe del Estudio Histórico y Lectura de Paramentos en la Iglesia parroquial de Nuestra Señora de las Nieves. Manzanares el Real, Madrid.

HERRERA CASADO, A. (1990). El Palacio del Infantado en Guadalajara. Guadalajara: AACHE.

QUINTANO RIPOLLÉS, A. (1954). Biografía de un Partido Judicial. Aportación de Colmenar Viejo a la Historia de España. Madrid: Diputación Provincial.

LAYNA SERRANO, F. (1931). El Palacio del Infantado de Guadalajara: Obras hechas a fines del Siglo XV y artistas a quienes se deben. Madrid: Hauser y Menet.

LAYNA SERRANO, F. (1935). Castillos de Buitrago y Real de Manzanares. Madrid: Nuevas Gráficas.

LAYNA SERRANO, F. (1993-1996) (1942). Historia de Guadalajara y sus Mendozas en los siglos XV y XVI. 4 Vols. Guadalajara: Aache Ediciones.

LÓPEZ GONZÁLEZ, A.L. (1974). El Real de Manzanares y su castillo. Madrid: Diputación Provincial de Madrid.

MADOZ, P. (1845-1850): Diccionario Geográfico-Estadístico-Histórico de España y sus Posesiones de Ultramar. 16 Tomos. Tomo XI. Madrid.

Madrid, Archivo Diocesano, Libro de Visitas 1591, cuentas 1500-1599, caja 1, Manzanares el Real. Fábrica, Fab. Pue. 3013 
Madrid, Biblioteca de la Asociación Cultural el Real de Manzanares, carpeta 16.

MAIRA VIDAL, R., FERNÁNDEZ DÍAZ, R. www.enjarje.com/investigacion/manzanares.html. [consulta: 01/04/2012].

MARCHAMALO SÁNCHEZ, A., MARCHAMALO MAÍN, M. (2011). Informe del Estudio Histórico Artístico en la Iglesia parroquial de Nuestra Señora de las Nieves. Madrid, Manzanares el Real.

MORENA B., Aurea de la (1976). Catalogo Monumental de Madrid. I. Colmenar Viejo. Madrid: CSIC.

NICOLAU CASTRO, J. (1997). "El Arquitecto Juan Guas en el V Centenario de su muerte". Toletum: Boletín de la Real Academia de Bellas Artes y Ciencias Históricas de Toledo, 36: 45-71.

PALACIOS GONZALO, J.C. (2009). La Cantería Medieval. La construcción de la bóveda gótica española. Madrid: Editorial Munilla-Lería.

PALOMO FERNÁNDEZ, G., RUIZ SOUZA, J.C. (2007). “Nuevas hipótesis sobre las Huelgas de Burgos. Escenografía Funeraria de Alfonso X para un proyecto inacabado de Alfonso VIII y Leonor Plantagenêt." Goya, 316317: 21-44.

PECHA, F. H. (1977) (1632). Historia de Guadalaxara. Guadalajara: Institución Marqués de Santillana.

RABASA DÍAZ, E. (2000). Forma y construcción en piedra. De la cantería medieval a la estereotomía del siglo XIX. Madrid: Akal ediciones.

WILLIS, R. (1910) (1842). On the Construction of the Vaults of the Middle Ages. London: The Royal Institute of British Architects.

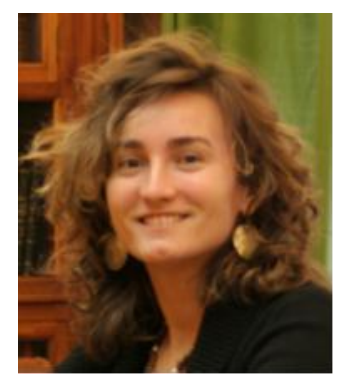

Rocío Maira Vidal.

rociomaira@enjarje.com

Enjarje Arquitectura. www.enjarje.com

Arquitecta y Máster en Restauración y Conservación del Patrimonio arquitectónico por la Escuela Técnica Superior de Arquitectura de Madrid (UPM). Actualmente está realizando su doctorado sobre estereotomía y construcción de bóvedas sexpartitas en el mismo centro. Al mismo tiempo ejerce su profesión en su propio estudio de arquitectura. Ha realizado diversos proyectos de restauración del patrimonio y levantamientos para la Dirección General de Patrimonio Histórico de la Comunidad de Madrid y el Arzobispado de Madrid.

Artículo recibido el 29/03/2012

Artículo aceptado el 24/08/2012 